\title{
Why customers and peer service providers do not participate in collaborative consumption
}

\author{
Simon HAZÉE \\ UCLouvain \\ Thijs ZWIENENBERG \\ KU Leuven \\ Yves VAN VAERENBERGH \\ KU Leuven \\ Tine FASEUR \\ KU Leuven \\ Audrey VANDENBERGHE \\ KU Leuven \\ Olivier KEUTGENS \\ HEC Liège \\ Forthcoming in Journal of Service Management
}

Simon HAZÉE is an Assistant Professor at the Department of Marketing, Louvain School of Mangement, UCLouvain, E-mail: Simon.Hazee@uclouvain.be

Thijs ZWIENENBERG is a Doctoral student at the Department of Marketing, KU Leuven, Belgium, E-mail: Thijs.Zwienenberg@kuleuven.be

Yves VAN VAERENBERGH is an Associate Professor of Marketing at the Department of Marketing, KU Leuven, Belgium, E-mail: Yves.VanVaerenbergh@kuleuven.be

Tine FASEUR is an Assistant Professor of Marketing at the Department of Marketing, KU Leuven, Belgium, E-mail: Tine.Faseur@kuleuven.be

Audrey VANDENBERGHE was a Master in Business Administration student at KU Leuven, Belgium. E-mail: Vandenberghe.Audrey@gmail.com

Olivier KEUTGENS was a Master in Management Sciences student at HEC Liège, Belgium, Email: KeutgensOlivier@gmail.com

Keywords: Collaborative consumption, innovation diffusion, innovation rejection, platform, triadic business models, sharing economy, digital transformation.

Article classification: Research paper

Acknowledgements: The authors thank Oliur Rahman Tarek as well as master students from HEC Liège for their help with data collection. 


\title{
Why customers and peer service providers do not participate in collaborative consumption
}

\begin{abstract}
Purpose: Technological innovations such as smart mobile devices and mobile applications gave rise to a new business model: collaborative consumption. This business model, which is receiving significant attention from researchers and practitioners, is characterized by an intermediating digital platform that facilitates exchanges between customers and peer service providers. However, many digital platform providers still fail to build a critical mass of demand and supply. Accordingly, the aim of this research is to develop a better understanding of the barriers perceived by both customers and peer service providers.
\end{abstract}

Design/methodology/approach: This study uses a mixed-method qualitative approach to develop a comprehensive understanding of the factors that explain the rejection of collaborative consumption. In particular, 6 focus groups and 14 in-depth interviews were conducted, totaling 50 Belgian participants (with a mean age of 33 years). In addition, 375 online critical incidentsretrieved from various sources, such as review websites and social networks—-were used for triangulation purposes. All data were analyzed using a thematic analytic approach.

Findings: Customers and peer service providers reject collaborative consumption because of a complex set of multidimensional functional and psychological barriers. In particular, actors may perceive barriers related to complexity, value, risk, compatibility, contamination, image, and responsibility, which prevent them from participating in collaborative consumption.

Originality/value: This paper builds theory on the reasons why both customers and peer service providers reject collaborative consumption. The research identifies several barriers that were not 
captured in prior research. Digital platform providers can use the research findings to more fully understand actors' decision-making processes in collaborative consumption.

Keywords: Collaborative consumption, Innovation diffusion, Innovation rejection, Platform, Triadic business models, Sharing economy, Digital transformation.

Paper type: Research paper 


\section{Introduction}

The digital revolution has tremendously changed the way people live and use services (Lamberton and Stephen, 2016). This ever-changing technological environment created new market opportunities. Among others, developments in digital capabilities as well as shifting individual preferences fostered the emergence of a new, innovative business model called collaborative consumption (Benoit et al., 2017). This triadic business model is characterized by an intermediating digital platform that facilitates exchanges among a network of actors (i.e., customers and peer service providers) through the extensive use of smart mobile devices (Perren and Kozinets, 2018). By using digital media, customers can easily and temporarily obtain access to peer service providers' underutilized assets, typically in exchange for a fee (Eckhardt et al., 2019). Examples of such disruptive digital services include Uber (ridesharing) and Airbnb (accommodation). Fehrer et al. (2018a, 2018b) propose that businesses in many industries face a digital transformation marked by high degrees of connectivity, ubiquitous technology, and peerto-peer engagement, among others, which will ultimately accelerate the rise of collaborative consumption. Andreassen et al. (2018) further propose that we are entering a new economy where traditional, employee-based business models will be merged with or even replaced by digitally enabled, triadic business models.

Despite the promising prospects of collaborative consumption, many organizations have failed to build a critical mass of supply and demand for their digital service (Andreassen et al., 2018; Täuscher and Kietzmann, 2017). For instance, the platforms BlackJet ("Uber for jet travel") and Tutorspree (“Airbnb for tutors") were withdrawn after only two years in operation due to a lack of both customers and peer service providers (Needleman and Loten, 2014). Despite its leading position in the Indian accommodation market, the digital platform Stayzilla 
also announced its closure in 2017 because of the difficulties in developing both market sides (Täuscher and Kietzmann, 2017). The lack of adoption of collaborative consumption by both customers and peer service providers highlights the need to understand the diffusion of collaborative consumption. Current studies on this issue mainly focus on understanding consumer acceptance and show that consumers engage in collaborative consumption because of convenience, economic, hedonic, environmental, and social benefits, among others (e.g., Guyader, 2018; Hamari et al., 2016; Mölhmann, 2015; Tussyadiah, 2016).

While these studies individually and collectively generate relevant insights for researchers and practitioners, at least two issues remain unresolved. First, despite the importance of understanding the reasons why customers engage in collaborative consumption, understanding the reasons why actors do not adopt collaborative consumption is equally important. The reasons against adoption of innovation differ qualitatively from the reasons for adoption (Antioco and Kleijnen, 2010) and require different strategies to be addressed (Kleijnen et al., 2009). Individuals — be they customers or peer service providers—disproportionally evaluate losses compared to benefits in their decision-making processes (Conchar et al., 2004; Kahneman and Tversky, 1979). To the best of our knowledge, only Tussyadiah and Pesonen (2018) offer some insights into customers' reasons for not using collaborative consumption. These authors examined three barriers (i.e., financial costs, complexity, and lack of trust) using a survey among Airbnb customers. Their use of a quantitative research methodology and focus on customers within one specific collaborative consumption setting, however, might impede the identification of new barriers for both customers and peer service providers and calls for a more extensive, qualitative study on these barriers across various digital platforms. 
Second, organizations that want to compete in the collaborative economy need to attract both customers and peer service providers to the digital platform (Kumar et al., 2018). Despite this observation, most research has investigated engagement in collaborative consumption from a customer perspective (e.g., Milanova and Maas, 2017), leaving the peer service provider perspective underexplored. However, when using collaborative consumption, peer service providers provide unknown customers access to their own personal assets, facing the risk that customers might damage the assets, be opportunistic, or misbehave in general (Andreassen et al., 2018). Hence, peer service providers might also face several reasons not to engage in the collaborative economy that may detrimentally affect the growth of such digital services and therefore need to be understood in more detail.

The purpose of this paper is to develop a comprehensive understanding of the barriers perceived by both the customer and peer service provider that impede the diffusion of collaborative consumption. With this effort, this research contributes to the literature in two main ways. First, by focusing on an emerging innovation such as collaborative consumption, this study extends the scarce research on innovation rejection, which has mainly focused on product innovations (e.g., Heidenreich and Kraemer, 2016; Kleijnen et al., 2009), or dyadic service innovations involving business-to-customer exchanges (e.g., access-based services; Hazée et al., 2017, 2019). Even though access-based services are closely linked to collaborative consumption (Benoit et al., 2017), the fundamental differences between both consumption modes underscore the need for additional research. Most notably, customers using collaborative consumption —as opposed to access-based services — acquire access to the personal assets of a peer service provider that are not owned or managed by a professional company (Kumar et al., 2018). By 
taking into account the complexities and specificities of collaborative consumption, this study uncovers specific barriers not captured by Hazée et al.'s (2017) research findings.

Second, this study complements prior research on barriers to service innovation by explicitly examining the barriers to collaborative consumption perceived by peer service providers. In doing so, the present research connects with Andreassen et al.'s (2018) observation that insights into the barriers that peer service providers face remain limited. Examining this perspective is both timely and relevant, especially since service work is changing from employee-based contracts to work arrangements within a work ecosystem (Subramony et al., 2018), such as the peer service provider within a collaborative economy (Benoit et al., 2017). While prior research conceptualized what attracts people to provide services in such a setting (Subramony et al., 2018), this research complements this perspective by outlining why people resist participating in collaborative consumption as a peer service provider.

Overall, this study connects with recent calls for more research on the psychological experience of participating in new digital services such as collaborative consumption (Lamberton and Stephen, 2016). From a practical perspective, the findings provide insights that would help digital platform providers identify the barriers perceived by both market sides prior to taking action to overcome the barriers and boost the adoption rate of their collaborative consumption offer.

\section{Innovation diffusion}

Understanding how customers react to innovations is considered a top research priority (Martin et al., 2016). The innovation diffusion literature is divided into two major research streams. The first stream focuses on the drivers of customer adoption/acceptance of innovation and is commonly based on the diffusion of innovation theory (Rogers, 1976), the theory of reasoned 
action (Fishbein and Ajzen, 1975) and the technology acceptance model (Davis et al., 1989). The second stream argues that rejection is conceptually separate from innovation adoption (e.g., Ram and Sheth, 1989) and stresses the importance of investigating the barriers that impede innovation adoption (Kleijnen et al., 2009). Despite their assumed relative advantage, few innovations become successful (Laukkanen, 2016). Identifying the barriers to innovation adoption accordingly represents a great opportunity for both researchers and practitioners.

The innovation diffusion literature broadly distinguishes two main types of barriers: functional and psychological barriers (for an overview, see Talke and Heidenreich, 2014). Functional barriers traditionally refer to complexity, value, and risk. Complexity barriers occur when customers perceive the innovation as too difficult to understand or use (Kleijnen et al., 2009). Value barriers refer to the lack of relative advantage (e.g., cheaper) or superior performance over alternatives (Talke and Heidenreich, 2014), whereas risk barriers ${ }^{1}$ arise if customers consider the innovation hazardous, such that it could cause harm to them (i.e., physical risk; Conchar et al., 2004), or when customers perceive uncertainties about the functionality or actual performance of the innovation (i.e., functional risk; Claudy et al., 2015). Psychological barriers, on the other hand, refer to compatibility and image. Compatibility barriers may arise when the innovation conflicts with traditions, norms, or routines (Karahanna et al., 2006), whereas image barriers occur when customers have negative associations regarding the brand or the innovation category (Kleijnen et al., 2009). Although these studies provide useful insights to explain the barriers that prevent customers from using (product) innovations

\footnotetext{
${ }^{1}$ Prior innovation research commonly considers the risk barrier as multidimensional, including physical, functional, economic, and social risk dimensions (Ram and Sheth, 1989). An innovation is considered as economically risky when it likely represents a bad value for the money, whereas social risks occur when an innovation conflicts with social norms and thereby creates likely disapproval from relevant social groups (Talke and Heidenreich, 2014). In line with Claudy et al. (2015) who question prior conceptualizations of rejection factors, this study strives for conceptual clarity and contends that the economic and social risks are captured by the value and compatibility barriers respectively.
} 
(Kleijnen et al., 2009), they may not be sufficient to capture the complexities of triadic service innovations such as collaborative consumption.

\section{Collaborative consumption}

\subsection{Conceptual foundation}

Collaborative consumption has been confounded with different types of exchange practices and confused with various terminologies, including access-based services (e.g., Schaefers et al., 2016), sharing economy (e.g., Kumar et al., 2018), access economy (e.g., Eckhardt and Bardhi, 2015), access-based sharing (e.g., Lu and Kandampully, 2016), or peer-to-peer services (e.g., Zervas et al., 2017). Although these exchange practices share some commonalities, namely, the absence of ownership transfer and the reliance on digital technologies to facilitate exchanges (Belk, 2014), they also differ in several ways. In particular, this research contends that collaborative consumption is different and unique in the sense that (1) it involves triadic exchange practices (i.e., platform provider-service provider-customer); (2) the digital platform provider does not own the resources or assets being (temporary) shared and is therefore able to scale up very rapidly; (3) the core service provider is usually a nonprofessional individual (also referred to as "peer service provider"); and (4) interactions between actors must occur to ensure service delivery (Benoit et al., 2017; Eckhardt et al., 2019; Perren and Kozinets, 2018). Moreover, collaborative consumption differs from traditional two-sided markets (e.g., eBay), which are more product-oriented and generate revenues from sales rather than short-term rentals (Kumar et al., 2018). Altogether, the specificities of collaborative consumption challenge traditional notions about marketing and call for new theory building (Parente et al., 2018).

\subsection{Why actors (do not) participate in collaborative consumption}


Despite the need to investigate both the benefits and the costs associated with collaborative consumption to understand its success variability (Andreassen et al., 2018), most prior research focuses on the reasons why customers and, to a lesser extent, peer service providers, intend to adopt and use these service innovations. Overall, this stream of research shows that customers are willing to use collaborative consumption because of economic (e.g., Barnes and Mattson, 2017; Milanova and Maas, 2017), hedonic (e.g., Lawson et al., 2016; Tussyadiah and Pesonen, 2018), social (i.e., status and sense of community; e.g., Guyader, 2018; Habibi et al., 2016), convenience (e.g., Mölhmann, 2015; Tussyadiah, 2016), and environmental benefits (e.g., Hamari et al., 2016). Moreover, customers prefer temporary access over ownership as the latter consumption mode is commonly associated with risks and responsibilities, including maintenance, repair, and storage of resources (e.g., Lawson et al., 2016; Moeller and Wittkowski, 2010). For peer service providers, their willingness to participate in collaborative consumption is mainly driven by economic benefits (i.e., reduction of ownership costs and opportunity for additional income; e.g., Wilhelms et al., 2017), as well as by social motives (e.g., Bucher et al., 2016) and autonomy (i.e., entrepreneurial spirit, flexibility, and need for independence; e.g., Kumar et al., 2018; Lehdonvirta et al., 2019).

These studies provide valuable insights into the adoption and usage of collaborative consumption. However, they do not explain why actors—both customers and peer service providers-do not engage in the collaborative economy. Hazée et al. (2017) empirically examine customer rejection of the access economy, especially of access-based services such as car- and bike-sharing programs, and show that customers reject such innovations because of complexity, reliability, and responsibility barriers, among others. While Hazée et al. (2017) provide a valuable contribution to the literature, the present study contends that the focus on customers 
only, in the access-based services context, may be too narrow in scope to fully understand the barriers to collaborative consumption. Although customers also acquire consumption time with assets when using access-based services (e.g., Zipcar), such self-services differ from collaborative consumption, as the latter implies that the assets being shared should not be owned by the firm but rather by peer service providers (Kumar et al., 2018) and that interactions between actors must occur to ensure service delivery (Benoit et al., 2017). These factors may create additional barriers, perceived by both customers and peer service providers.

In summary, early research on innovation diffusion identified both similar and specific barriers that withhold people from adopting more traditional innovations and access-based services (see Table 1). This study contributes to the innovation diffusion literature by investigating the barriers to participation in collaborative consumption as perceived by both customers and peer service providers. Given the unique characteristics of collaborative consumption, this research contends that barriers distinctive from the other business models might arise. To enhance this understanding, this study addresses the following two central research questions:

$R Q 1$. What are the perceived barriers that lead customers to reject collaborative consumption?

$R Q 2$. What perceived barriers lead peer service providers to reject collaborative consumption?

[Table 1 here]

\section{Method}

The need for more insights into the reasons why actors do not participate in collaborative consumption calls for the use of a qualitative, mixed-method research approach, which is 
deemed appropriate when a given phenomenon is poorly understood and still needs to be explored (Strauss and Corbin, 1990). The mixed-method approach is particularly beneficial in view of the inherent complexity of the service phenomenon that is collaborative consumption. The plurality of perspectives embedded in each research method would indeed lead to richer and more robust results (Hesse-Biber, 2010).

\subsection{Qualitative study}

\subsubsection{Focus groups}

Focus groups are particularly appropriate for the purpose of this study, as the group dynamics occurring through interactions help participants disclose their experiences, concerns, and opinions (Morgan, 1997). Data were collected using established procedures (e.g., Kitzinger, 1995). The focus groups began with a friendly welcome as well as a presentation of the study and the moderator, followed by short exercises to generate a nonjudgmental environment conducive to self-disclosure (Morgan, 1997). Participants participated in a brainstorming exercise to generate examples of services and companies associated with collaborative consumption. The moderator then used the examples to drive the group discussion. The moderator used a semistructured discussion guide that included the main topics to cover, along with prompts and follow-ups. During the discussion, the moderator ensured the customer and peer service provider perspectives were captured by asking all participants to reflect on and discuss both perspectives. This approach was deemed appropriate as anyone can become a customer and/or a peer service provider in collaborative consumption (Kumar et al., 2018). Focus groups lasted 69 minutes on average.

\subsubsection{In-depth interviews}


In addition to focus groups, interviews were conducted to enable a more in-depth understanding of the barriers associated with collaborative consumption. The protocol used during the focus groups was also used for individual interviews, albeit with some minor adaptations. For instance, in the first part, general questions (e.g., "Please tell me what you think about collaborative consumption") were asked to prompt replies about respondents' personal experiences before asking more specific questions about their concerns or reasons against the adoption and usage of such services. The last part of the interview guide included questions about the concepts that emerged from the focus groups. Interviewees were asked to reflect on these specific concepts. During the interviews, the interviewer used prompts (e.g., "Please tell me more about that") to encourage participants to elaborate on their answers. Respondents were also asked to provide contextual details as well as examples (e.g., "Can you give me an example of what you mean?”) to avoid misinterpretation of the data (Wallendorf and Belk, 1989). Interviews lasted 40 minutes on average.

\subsubsection{Data collection and sample}

Respondents were obtained using a nonprobability, theoretical sampling scheme. In particular, participants were recruited through the authors' personal networks as well as notice boards (e.g., university hall). All participants lived in Belgium, where numerous collaborative consumption platforms are available (Basselier et al., 2018). To ensure a comprehensive understanding of the rejection of collaborative consumption, the authors checked for the heterogeneity of the sample and balanced it across different characteristics such as gender, age, professional status, and prior experience. Including respondents who specifically differ in terms of prior experience with collaborative consumption reflects the observation that rejection may not only occur before but also after adopting the innovation due to continued uncertainty (Talke and Heidenreich, 2014). 
The sampling process ceased when theoretical saturation was reached, that is, when no new information emerged from the data (Patton, 2014). In total, 6 focus groups (each group was composed of 6 individuals) and 14 in-depth interviews were conducted, totaling 50 Belgian participants. Among them, 17 were men and 33 were women, all of whom were aged between 21 and 63 (with a mean age of 33 years) (see the appendix for more information about the respondents).

\subsection{Critical incident study}

In addition to focus groups and in-depth interviews, the authors collected online secondary data. This study followed the Critical Incident Technique (CIT) procedures for collecting, analyzing, and classifying observations of human behaviors — or incidents - that have critical significance for understanding the phenomenon of interest (Gremler, 2004). Online posts describing an individual's concerns, doubts, perceived barriers, or negative experiences about collaborative consumption were considered critical incidents. Collecting incidents describing past negative experiences with collaborative consumption was specifically deemed suitable to better understand why individuals rejected these services.

Incidents were retrieved from various sources, such as review websites, forums, and social networks (e.g., Trustpilot, Reddit, Sitejabber, Facebook). When possible, the authors used the international version of these online sources as a means to check for the cultural heterogeneity of the data. When this was not possible, the webpage version that contained the most online posts was selected. As a result, incidents were collected in several countries and markets (e.g., France, the United States, United Kingdom) where numerous collaborative consumption initiatives are available. The data collection was limited to the six companies that were the most frequently mentioned by respondents in the qualitative study (namely, Airbnb, BlaBlaCar, Deliveroo, Fat 
Llama, TaskRabbit and Uber), thereby extending previous studies on collaborative consumption that mainly focus on Airbnb (e.g., Tussyadiah and Pesonen, 2018; Zervas et al., 2017). In line with similar studies using CIT (see Gremler, 2004), approximately 60 incidents per company were collected, based on their order of appearance (i.e., only the most recent incidents were included in the study), for a total of 375 incidents. Incidents were then classified according to the focal perspective taken by the individual who wrote the online post. If an individual shared an incident as a customer (or peer service provider), this post was classified as taking a customer (or peer service provider) perspective. In the end, 231 incidents involved the customer perspective, and 144 incidents involved the peer service provider perspective. The insights gained from the critical incident study were mainly used to triangulate and validate the qualitative study findings.

\subsection{Data analysis}

All data were analyzed using a thematic analytic approach, which is an iterative process that organizes and describes data in rich detail (Braun and Clarke, 2006). The thematic analysis involved four steps. First, the data were read several times to become familiar with them. Initial ideas were noted down. In a second step, the data were coded verbatim, line by line. The authors used both theoretical codes identified in the literature (e.g., complexity barrier; Kleijnen et al., 2009) as well as inductive codes. The latter allowed the researchers to capture new barriers emerging from the data (Strauss and Corbin, 1990). At this step, the authors developed a coding plan that listed all identified barriers perceived by customers and/or peer service providers, together with descriptions and illustrative statements. The coding plan was jointly reviewed and discussed for the sake of internal consistency. In a third step, prior complementary literature (e.g., innovation diffusion) was integrated into the codes, and relationships among codes were 
searched for. In the last step, the author team developed higher-order, thematic groupings of the identified codes.

\subsection{Trustworthiness assessment of the results}

The credibility and objectivity of the findings were assessed using several established

procedures. In particular, the researchers applied both data and researcher triangulation (for a similar procedure, see Homburg et al., 2017). For the data triangulation, the results emerging during the analysis were carefully compared with supplementary research streams (e.g., innovation diffusion, customer resistance, access-based services); the latter streams were integrated in the analysis to extend prior knowledge (Strauss and Corbin, 1990). In addition, the results of the interviews and focus groups were systematically compared with the secondary data obtained in the critical incident study. The transferability of the identified concepts was further checked and confirmed across the different examples of services mentioned during the focus groups and interviews, as well as in the collected incidents (e.g., Airbnb, Uber, TaskRabbit, Lyft, Peerby), to increase generalizability (Homburg et al., 2017).

For the researcher triangulation, the authors discussed the codes and jointly categorized them into theoretical themes while ensuring consistency and seeking agreement through discussion. Finally, two independent judges — both of whom were familiar with qualitative research — were asked to assign a sample of randomly selected statements to the abstract categories that we developed to ensure the reliability of the categorization. The interjudge reliability—assessed following the Proportional Reduction in Loss measure — reached 0.81, which is well above the 0.70 threshold recommended for exploratory research (Rust and Cooil, 1994). 


\section{Results}

As depicted in Table 1, seven abstract categories of barriers that impede customer as well as peer service provider adoption and usage of collaborative consumption were identified: complexity, value, risk, compatibility, contamination, image, and responsibility barriers. All categories are disaggregated into various dimensions that can further explain the rejection of collaborative consumption. While some barriers and dimensions overlap with prior research findings on rejection of product innovations (e.g., Kleijnen et al., 2009) and dyadic business models such as access-based services (e.g., Hazée et al., 2017), several other findings seem to be specific to the unique, emerging phenomenon that is collaborative consumption. In the next subsections, the new findings uncovered by this research are presented in more detail and discussed against prior research.

\subsection{Functional barriers}

\subsubsection{Complexity barrier}

Prior innovation research has long investigated the complexity barrier (Talke and Heidenreich, 2014) and broadly conceptualized it as the difficulty associated with understanding and using the (product) innovation (Kleijnen et al., 2009). In collaborative consumption, the complexity barrier not only refers to the perceived difficulty associated with the understanding and usage of the innovation but also with its accessibility and the organization of the transaction. In line with prior research on access-based services (e.g., Hazée et al., 2017), customers consider collaborative consumption to be complex because these services are difficult to access, understand, use, and it is difficult to make transactions. For instance, customers perceive difficulties in getting access to the shared asset (e.g., apartment), which requires them to coorganize (with the peer service 
provider) the service delivery and carefully check the state of the shared asset. As one respondent mentions:

How do you pick up the keys? Because sometimes the owner doesn't live there, you must find a solution, organize the meeting, and then meet, and then what if the key doesn't work? And you cannot reach out to the owner? (customer) ${ }^{2}$

Digital platform providers try to filter actors through the use of detailed registration processes. Although these practices are introduced to ensure interpersonal trust between customers and peer service providers, actors paradoxically believe that this procedure makes the accessibility of collaborative consumption even more complex:

Crazy rigorous ID verification system! They asked for gov ID (Ok, makes sense), then proof of address, then asked for all my social media, boss's phone number?! And for a friend to also verify?!?! And not only would they have to go through the crazy verification system, they would have to pay for something before they do! (customer)

Peer service providers may also perceive this multidimensional complexity barrier, which may hinder their acceptance of collaborative consumption. For instance, peer service providers are more likely to reject collaborative consumption when they face difficulties in ensuring the shared asset is in order (e.g., in terms of safety) or in meeting with customers and explaining to them the shared asset usage rules (accessibility dimension):

Just wondering what happens first? You get notified when a client hires you? Then, I know I have to reply to the client in less than an hour. But what should I say or ask? Should I just accept the task or...? (peer service provider) One of the main reasons why hosts decide to stop being a host is because they find that guest communication takes too much time! (peer service provider)

\footnotetext{
${ }^{2}$ In order to protect the respondents' identity, this study provides complete anonymity and only mentions the perspective (customer or peer service provider) taken by the respondent.
} 
Although both customers and peer service providers may similarly experience the complexity barrier, the data reveal that differences across types of actors may occur at a more concrete level. This outcome suggests that disaggregating the abstract constructs with regard to the contextspecific issues that might arise may be particularly important in order to best understand actors' decision-making process. For instance, the complexity barrier in collaborative consumption refers, among others, to asset scarcity (accessibility dimension) — that is, the extent to which an asset (e.g., a room or a car) is available whenever needed (Lamberton and Rose, 2012) — and difficulties paying invoices (transaction dimension) for customers. These dimensions would capture the following contextual issues for peer service providers: "getting the apartment up to safety standards by providing fire extinguishers" and "setting and justifying prices".

\subsubsection{Value barrier}

In line with prior research on (product) innovation diffusion (e.g., Talke and Heidenreich, 2014), the value barrier in collaborative consumption refers to the lack of economic benefits (value for money) or relative advantage over alternatives. Both customers and peer service providers indeed question the superiority of collaborative consumption in general and of specific platforms in particular, compared to ownership and/or other services. For instance, actors may reject collaborative consumption because they worry about the size of the platform's network in terms of demand and/or supply, which is commonly considered a strong competitive advantage for companies operating in two-sided markets (also referred to as the "network effect"; Eisenmann et al., 2006). Disaggregating the value barrier with regard to the contextual issues that might arise reveals that customers are concerned about the high commission charged by platform providers, which lowers the users' economic benefits, as well as about the poor-quality of customer support. Peer service providers also question the economic value of collaborative 
consumption given the difficulties in predicting future financial earnings. Altogether, these value-related aspects are likely to explain why actors reject collaborative consumption. In the respondents' words:

There are not enough taskers on this platform, and frequently, the same tasker comes up no matter what you put in... (customer)

The platform won't put any effort into resolving bad reviews or issues with clients... the customer service won't do anything about it, and you will get the runaround but never real help! (peer service provider)

The platform takes 30\% of the tasker's money, which is astronomical; so, a tasker is much more expensive than would be expected because they up their rates to pass the expense onto the person booking! And wait... the platform also charges a service fee for the booking!!! (customer)

It has not been a sustainable position for myself... the hardest part of the job is the instability of the market for work. (peer service provider)

\subsubsection{Risk barrier}

The risk barrier in collaborative consumption refers to actors' uncertainty perceptions about the functionality of the innovation (as reflected in the shared assets, the digital platform, and other actors) as well as about their personal safety and privacy. Prior innovation research mainly focuses on product-related risks, such as the product performance dimension of risks (or functional risk; Kleijnen et al., 2009). The data suggest that functional risks associated with platform technology also appear to be of great concern for actors in collaborative consumption. This is especially important for peer service providers who are in a difficult social situation and depend solely (or largely) on the platform for an income. In particular, actors (especially peer service providers) might feel vulnerable when they perceive a high dependence on the platform 
given the potentially severe negative consequences incurred (e.g., financial consequences), which may explain why they do not participate in collaborative consumption. In one respondent's words:

After a divorce, I stared doing Airbnb to make ends meet [...] One day, one of my regular guests mentioned that he couldn't rebook due to an error in the app. I called Airbnb; they informed me that they will send this case to the specialist department to be fixed. My app froze and my guests were leaving because they couldn't rebook. I called back again and again to see what was going on?! Again, the same answer [...]. Then, Airbnb started cancelling the few guests I had left and refunding them out of my monthly earnings! I begged Airbnb; I told them that this was my only income and that the money they were returning was in fact my rent for myself and my boys. Again, same answer. I suspect it was just a glitch in the app that they didn't feel like fixing... (peer service provider)

The functional dimension of the risk barrier not only relates to the products (shared assets) and technology (digital platform) but also to other actors. The data suggest that customers and peer service providers indeed reject collaborative consumption because of perceived uncertainties related to the performance of the service counterpart (peer service provider or customer). Despite the numerous actions taken by platforms to bolster trust among actors and ensure good service performance (e.g., governance systems, ratings, verified profiles; Hartl et al., 2016; Tussyadiah and Pesonen, 2018), customers question the reliability of peer service providers and, by extension, the functionality of the assets made available by peers, as the latter are commonly not perceived as professional experts. Likewise, peer service providers tend to believe that customers behave differently and are less respectful (e.g., context-specific issues include "not arriving within stated check-in time without warning" and "stealing stuff such as mouthwash, deodorant, hygiene products that were kindly provided for use"), when they deal with peer service providers 
compared to professional companies, which may lead to potential negative consequences. Accordingly, peer service providers also worry about the uncertain performance of customers in collaborative consumption, that is, the extent to which customers will perform their role on a consistent and accurate basis. As four respondents explain:

Booked and paid for a place in $* * * * *$, only to not get a reply and was cancelled [...] never again! And it's a common thing with their hosts to not honor bookings. (customer)

I attempted to message with this guest and thought we were on the same page insofar as the House Rules. We were not; my home was destroyed by this guest and his band of cigarettesmoking animals. (peer service provider)

A "tasker" came to replace the plug in our bath and forgot to reconnect the drainage pipe! We then suffered electrical and cosmetic damage from the ensuing leak! (customer)

I travel a lot, so I was putting my apartment on Airbnb from time to time. People are disrespectful to your stuff, to your home! They treat your home like some cheap hostel, even though I still live there, and everything is new and tastefully decorated. They also stole few of my books too. Never again. (peer service provider)

As highlighted in the following statement, the data further suggest that customers consider the functional dimension of the risk barrier as a strong reason for switching to alternative services delivered by professional organizations (including access-based services) rather than peers. Customers would even be ready to pay a price premium to lower uncertainties related to the service performance. In one respondent's words:

Even though taxis are usually more expensive, at least you know there's a company behind them! I don't really know about Uber drivers, I mean I don't know who they are, these are not professional people so... you have more uncertainties. (customer)

In addition to the functional dimension of the risk barrier, prior innovation research shows that individuals may experience physical risk barriers when they consider a product innovation to be 
hazardous, such that the (product) innovation could incur harm to them (Conchar et al., 2004). In service innovations such as collaborative consumption, actors are also concerned about their personal and physical safety. The data yet reveal that physical risks are not only associated with the (shared) product itself, as conceptualized in prior innovation research (e.g., Kleijnen et al., 2009) but also with the service counterpart (customer or peer service provider). Both customers and peer service providers indeed feared being physically assaulted, robbed, kidnapped, or raped. As two respondents explain:

I wouldn't like traveling alone with a stranger, especially since I am a woman, this is an important issue to me. The same goes for Airbnb, the host has the keys, so he could always come in, what if it's a trap or something? What if something happens to me? Safety is my main concern. (customer)

You never know whose home you are walking into, and at times you can feel very unsafe. (peer service provider)

A third dimension of the risk barrier refers to actors' privacy concerns and perceived uncertainties related to their personal data (e.g., fear of data theft) as well as intimacy. As opposed to prior research that shows customers adopt and use collaborative consumption because of social benefits (e.g., Bucher et al., 2016), the results reveal that actors may be reluctant to share objects, rides, or spaces because of the likelihood of social interactions implied by the presence of others, which may conflict with their need for intimacy and potentially create negative consequences (e.g., physical and psychological discomfort). The following statements illustrate this dimension:

When I travel, I need privacy you know. I want to do what I want, if I want to talk loudly and walk around in my underwear, I just want to do it. When using sharing services, you cannot always do this, as you share the car, the house, etc. with other people. (customer) 
Another barrier to me is the social or private aspect. Sometimes you meet people who are "oversocial”. I mean ... you sometimes feel obliged to talk to people when using BlaBlaCar. (customer)

\subsection{Psychological barriers}

\subsubsection{Compatibility barrier}

Echoing prior innovation research (e.g., Karahanna et al., 2006), the data suggest that the compatibility barrier in collaborative consumption is best conceptualized as a multidimensional construct. In particular, compatibility barriers arise when collaborative consumption conflicts with actors' previous experience, social values, and usage patterns. Given the absence of a common law framework across countries regulating collaborative consumption (Light, 2018), conflicts with one's social values can occur. For instance, actors may find collaborative consumption incompatible with their values because of the perceived illegal aspect of these exchanges (e.g., unfair competition, tax avoidance). Even though collaborative consumption may be regulated in some countries, actors still question the morality of these practices; they specifically worry about their exploitative nature, which would contribute to collective value destruction (e.g., lower wages, more time pressure, less job security, asocial working hours): As soon as you are offering a service, you must be legally in order! [...] When you use these platforms, you're considered self-employed, you receive income, and must pay taxes. But that's not true, most people don't! I dislike and reject this, it's a matter of social values. (peer service provider)

Ijust heard that some drivers earn $£ 2$ an hour. The official response is that workers are freelance apparently. It's lawful but is it morally correct? One of their job ads I saw insinuated that I could earn more than a doctor with them. What a bunch of *****s. App removed. (customer) 
In addition to negative prior experiences with a similar service or conflicts with their social values, actors may also worry about the compatibility of collaborative consumption with their usage patterns, current practices, or lifestyle. Using innovations such as collaborative consumption requires one to change his/her consumption or working habits and to manage time differently, which may create actor resistance. This dimension of the compatibility barrier appears to be even more salient when actors lead a busy lifestyle:

My fear is signing up to do this stuff and then getting hit with a ton of jobs I can't handle [...] this would be challenging at times due to busy lives and schedules. (peer service provider)

\subsubsection{Contamination barrier}

Similar to prior research on access-based services (e.g., Hazée et al., 2017, 2019) and secondhand products (e.g., Kapitan and Bhargave, 2013), the data show that customers and peer service providers may also experience contamination concerns about the assets being shared in collaborative consumption because these assets have (or are likely to) come in physical contacts with previous customers and/or the peer service provider who owns the assets. Put differently, contamination arises when an individual believes that the asset of interest has been touched by someone else, which can create feelings of disgust as well as fear of being contaminated (Argo et al., 2006). Although assets (e.g., room) being shared via collaborative consumption are likely to be touched by a lower number of persons compared to traditional companies (e.g., hotels), the contamination barrier seems to be salient for both customers and peer service providers because actors do not know how the shared assets were used before or whether the assets were cleaned properly between each usage. Moreover, when using collaborative consumption, actors have the feeling of entering someone else's personal sphere (or letting someone enter one's sphere, depending on the perspective), which may trigger repulsion and explain why contamination is more important in collaborative consumption compared with traditional, employee-based 
business models (Morales et al., 2018). The data further suggest that the contamination barrier would be particularly salient when actors have feelings toward an object, that is, psychological ownership (Bagga et al., 2019). In two respondents' words:

After going back to the apartment, one of us became very itchy. She was lying on the bed for a while. We thought this could be due to the sea salt, as we had had a day at the beach. But then it became even worse; we carefully looked at her and noticed her arms and legs were full of bites! Bed bugs! We left the apartment and refused to pay for such a dirty slum! (customer)

I wouldn't like to know that some people are using and touching my stuff, wearing my jeans and doing things in my bed... I would feel too uncomfortable. (peer service provider)

\subsubsection{Image barrier}

This barrier refers to unfavorable associations regarding the platform provider's brand, the innovation category, and one's own brand. Given the triadic nature of collaborative consumption, which heavily relies on reputation systems (Andreassen et al., 2018), actors are not only concerned about the firm brand (i.e., the platform provider) and the innovation category but also about their own personal brand. Customers as well as peer service providers are indeed likely to be evaluated and rated by their counterparts. Accordingly, actors worry about the qualities (or lack thereof) that other customers or peer service providers might associate with them, as their own image or reputation will be taken into consideration in subsequent service requests and offers. This "reputation economy", as called by one respondent, would place actors under pressure and accordingly create resistance:

You know you will be rated, so I always try to be as polite as I can be, say thank you, don't eat or drink in the car, don't talk on the phone, and try to be the best possible guest I can be, but there's always some... you never know how good your rating will be you know, that's a big 
concern. And if you have a bad rating, then no one will accept your requests, you may even be excluded! (customer)

The data further suggest that the image barrier is salient for both customers and peer service providers. On one hand, being publicly evaluated by service providers is perceived as rather new by customers, which makes this barrier particularly salient for them. On the other hand, customers would have high expectations and a rather narrow zone of tolerance (their points of reference usually being services provided by professional businesses), which makes it difficult for peer service providers to offer adequate service performance and foster a positive image. In one respondent's words:

Sometimes customers may have high expectations, as if we were professionals; so, when we go and do a job, they expect that we do the job in a very professional way, and then they may complain and write a bad review on your page! That's my main concern, this is a major flaw in the system. (peer service provider)

The image barrier has been extensively examined in prior innovation research, which conceptualizes it as customers' negative associations regarding the firm brand and the innovation category (Ram and Sheth, 1989). However, this conceptualization was initially developed in relation to product innovations (Kleijnen et al., 2009), such that it might not capture all the complexities inherent to service innovations, especially those that heavily rely on reputational governance systems to manage all actors involved in service production and delivery. By taking into account the unique characteristics of triadic business models, this study uncovers a new dimension, namely, one's personal brand, that might better explain the effects of the image barrier on the rejection of collaborative consumption.

\subsubsection{Responsibility barrier}


The responsibility barrier refers to actors' concerns about being held responsible for their own or other actors' usage of the innovation or of the shared assets. Claudy et al. (2015) consider liability following an accident as a customer-perceived barrier to access-based services such as car-sharing. In a similar vein, customers may reject collaborative consumption because they worry about being held responsible for their own usage of the shared objects or spaces:

The insurance policy for borrowers does NOT exist! If you will break, lose, etc. the borrowed equipment, on top of $\$ 118.50$, you are reliable for a full price of a new same type of equipment, even if you have borrowed a used one! (customer)

In addition, actors may also worry about their responsibility for others' usage of the shared assets. Hazée et al. (2017) show that customers of access-based services are concerned about being held responsible for other customers' usage of the goods (e.g., car, bike, toys). Given the triadic nature of collaborative consumption, this study extends prior conceptualization of the responsibility barrier and proposes that customers not only fear of being held responsible for previous customers' usage of the shared assets but also for the peer service provider's behavior. Similarly, the responsibility barrier may explain why peer service providers reject collaborative consumption, as they are concerned about their liability in case of customer misfortune (e.g., accident during service delivery) or misbehavior (e.g., shared assets damaged by customers). The following statements illustrate this barrier:

I really don't know who the guest will be, how he or she will behave. I know I can complain, but what if something goes wrong? Who would be held responsible? Me? The guest? Airbnb? Actually, I don't really feel protected. If someone steals something, what's Airbnb gonna do? (peer service provider)

It's just totally unfair that I had to pay over $\$ 100$ for someone else's mistake and negligence! (customer) 
Overall, this study demonstrates how switching from a traditional business model focused on ownership or employee-provided service to a digital platform-enabled business model creates a complex set of unintended functional and psychological barriers that may impede actors from participating in collaborative consumption.

\section{Theoretical contributions}

Despite the need to better understand why individuals do not adopt and use service innovations, prior research offers limited insights into the barriers associated with the emerging digital service innovation that is collaborative consumption. This research accordingly addresses recent calls for more research on rejection of service innovations in general (Martin et al., 2016) and of collaborative consumption in particular (Andreassen et al., 2018).

By focusing on collaborative consumption, considered as a unique service innovation (Kumar et al., 2018), this study extends the emerging research stream on innovation rejection, which has mainly focused on product innovations (e.g., Heidenreich and Kraemer, 2016; Kleijnen et al., 2009) or dyadic service innovations involving business-to-customer exchanges (e.g., access-based services; Hazée et al., 2017, 2019). Specifically, this research accounts for the complexities of triadic service innovations and conceptualizes several multidimensional actorperceived barriers, whose dimensions seem to be specific to collaborative consumption. For instance, the image barrier is commonly conceptualized in the innovation literature as customers' negative associations regarding the country of origin of the innovation, the innovation category, or the firm brand (e.g., Kleijnen et al., 2009; Ram and Sheth, 1989). The present results suggest actors also worry about their own brand - or personal image - in collaborative consumption given the platform provider's heavy use of reputation systems, which may explain why they do not participate in collaborative consumption. 
Similarly, the functional dimension of the risk barrier in collaborative consumption not only relates to product performance (shared assets performance in this case), as generally conceptualized in innovation research (Talke and Heidenreich, 2014) but also to uncertainty perceptions about the functionality of the digital platform and other actors (customer or peer service provider). Moreover, this study reveals that actors may perceive psychological barriers other than compatibility and image (e.g., Karahanna et al., 2006; Kleijnen et al., 2009). Actors may indeed experience contamination concerns about the assets being shared in collaborative consumption because the latter have (or are likely to) come in physical contact with previous unknown customers as well as with the nonprofessional, peer service provider who owns the shared asset. By focusing on the barriers that impede actor participation in collaborative consumption, this study also extends the emerging research stream on collaborative consumption, which has mainly investigated the benefits driving customer acceptance (e.g., Hamari et al., 2016; Milanova and Maas, 2017; Tussyadiah, 2016).

In line with Randhawa et al.'s (2016) recent call for more innovation research, including perspectives other than the firm perspective, the present study's use of a multiuser perspective creates a more comprehensive understanding of innovations. Addressing Andreassen et al.'s (2018) observation that insights into the barriers perceived by peer service providers remain limited, this study captures both market sides (customers and peer service providers) and accordingly extends prior research by providing a fine-grained analysis of the dual rejection of the collaborative economy. For instance, the results show that customers experience uncertainties related to peer service providers' performance since the latter are not considered professional experts. On the other hand, peer service providers also question the extent to which customers will perform on a consistent and accurate basis. Peer service providers indeed worry about the 
fact that customers behave differently in collaborative consumption and are less respectful when dealing with peers compared with professional companies. Taken together, these results show that the risk barrier might not only explain customer rejection but also peer service provider rejection of collaborative consumption.

Given the decline of traditional employer-employee relationships and the expected growth of new work arrangements in the future (Subramony et al., 2018), this study shows that peer service providers in the collaborative economy need to be attracted and managed quite differently from "regular" workers. Whereas regular workers can be attracted to an organization using employer image and branding tactics (Lievens and Slaughter, 2016), organizations seeking to attract peer service providers to the platform also need to help them overcome the barriers associated with this type of professional activity.

Surprisingly, the results suggest that all barriers and their respective conceptual dimensions are identical for both customers and peer service providers. This study, however, contends that differences may occur at a more concrete level. For instance, although the following issues similarly illustrate the accessibility dimension of the complexity barrier, they yet differ across actors at a more contextual level: "fear of apartment unavailability" for customers and "getting the apartment up to safety standards" for peer service providers. Hence, disaggregating the abstract constructs with regard to the context-specific issues that might arise may be particularly important in order to best understand actors' decision making process (Claudy et al., 2015). Put differently, all barriers should be operationalized according to contextual issues that are specific to collaboration consumption, which may differ across types of actors (customer or peer service provider). In line with behavioral reasoning theory (Westaby, 2005), this study argues that 
including context-specific issues when testing innovation diffusion models would specifically provide a more complete understanding of the phenomenon.

This research also provides insights into an ongoing debate about the collaborative economy in general. In several comments and incidents, respondents argue that the reliance on a peer service provider (and hence, the absence of a professional service provider) makes them reject collaborative consumption. These observations outline a rather paradoxical situation. On the one hand, the involvement of professional organizations is heavily criticized for making collaborative consumption a form of neoliberal capitalism, away from the social values inherent to the initial development of "sharing" platforms (Martin, 2016). On the other hand, the involvement of professional organizations could actually convince more customers to adopt and use collaborative consumption, which is needed for its development and growth.

\section{Managerial implications}

Many digital platform providers fail to build a critical mass of supply and demand (Täuscher and Kietzmann, 2017). The present findings accordingly provide useful insights for these firms that wish to invest in collaborative consumption. In particular, digital platform providers can use this study's results to examine the specific barriers that customers and peer service providers associate with their digital service. The present findings may specifically help firms identify the rejection factors that are likely to influence the participation of both market sides. The results show that customers and peer service providers reject collaborative consumption because of complex functional (complexity, value, and risks) as well as psychological barriers (compatibility, contamination, image, and responsibility). The findings and illustrative statements, derived from field data, provide insightful examples of actor-perceived barriers as 
well as of their respective underlying dimensions. Altogether, these results should help firms identify which barriers they should overcome to boost the adoption rate of their digital service. Further research is necessary to develop efficient firm strategies aimed at overcoming the barriers identified in this study.

\section{Limitations and future research}

As with any study, the results of this study are subject to some limitations, which offer potential fruitful avenues for future research. Given the exploratory nature of our results, empirical verification of the present findings is needed. In particular, future research could develop and validate new scales of actor-perceived barriers related to collaborative consumption. The results, grounded in field data, provide useful insights for developing relevant measures that can further be linked to various outcomes such as customer and peer service provider attitudes as well as adoption intentions. A logical next step would also be to test the relative importance of all the barriers identified in this study across both market sides (customers and peer service providers); differences in terms of magnitude may indeed occur depending on the consequentiality of the perceived barriers. For instance, actors (especially customers) seem to worry more about their personal safety (risk barrier), rather than the image of the innovation category (image barrier), given the potentially more severe negative consequences associated with the former (e.g., physical and psychological consequences of being physically assaulted). Similarly, the accessibility dimension of the complexity barrier seems to be more important for potential peer service providers compared with customers, given the high initial investment needed to initiate the service delivery. Investigating these potential relative differences in more detail would provide managers with useful insights on which barriers to focus first, to reduce rejection of their 
offer. Future research might also use the barriers identified in this study as potential (behavioral) segmentation criteria within collaborative consumption, as doing so would help digital platform providers make better targeting as well as matching decisions (Lutz and Newlands, 2018).

Second, authors have argued that the importance of specific factors may change across time and adoption stages (e.g., Venkatesh et al., 2012). For example, the complexity barrier may fade away once individuals have more experience with collaborative consumption and are used to using it. Conversely, the contamination barrier would remain important as avoiding disease is intrinsically considered an evolutionary challenge, or fundamental motive, that influences human behaviors (Griskevicius and Kenrick, 2013). Against this backdrop, future research could examine, in a longitudinal study, whether the barriers identified in this study gain (or lose) importance over time. Doing so would provide a more comprehensive and dynamic understanding of actors' production and consumer journey in collaborative consumption (Dellaert, 2019).

Third, further research is needed to develop efficient firm strategies aimed at overcoming the barriers identified in this research. Understanding how to reduce rejection of innovations is crucial for firms and considered a top research priority (Heidenreich and Kraemer, 2016). Such an understanding is even more necessary since overcoming barriers would require different strategies than those aimed at promoting acceptance (Kleijnen et al., 2009). Given the importance of considering context-specific barriers to understanding individuals' decision making (Claudy et al., 2015), more research on context-specific rejection-reduction strategies that would account for the complexities and specificities of collaborative consumption is especially needed. 
Fourth, understanding innovation diffusion across cultures remains particularly needed (Peres et al., 2010). Culture might shape how actors evaluate collaborative consumption (Davidson et al., 2018), such that some barriers might be more (or less) important according to one's cultural background. For instance, the reliability barrier (as reflected in the dimension: other actors' reliability) may especially be relevant among individuals with a high individualistic (versus collectivistic) cultural orientation. Similarly, the contamination barrier would likely be more significant for individuals who score high on power distance due to their tendency to strongly react to personal threats (Taylor, 2000). Given the growing prevalence of collaborative consumption worldwide, investigating the effect of culture on rejection is also needed.

Fifth, examining how actors evaluate collaborative consumption in emerging economies is especially needed given the potential positive effects of such service innovations on collective well-being (Belk and Llamas, 2012). In particular, global digital platforms enable individuals from emerging-economy countries to choose microprovidership, which may provide a better return on their skills compared with traditional employment in a local firm (Lehdonvirta et al., 2019). Such an investigation would further help in understanding the role of service innovations at the base of the pyramid (Reynoso et al., 2015). 


\section{References}

Andreassen, T., Lervik-Olsen, L., Snyder, H., Van Riel, A.C.R., Sweeney, J.C., and Van Vaerenbergh, Y. (2018), "Business model innovation and value-creation: The triadic way", Journal of Service Management, Vol. 29 No. 5, pp. 883-906.

Antioco, M., and Kleijnen, M. (2010), “Consumer adoption of technological innovations”, European Journal of Marketing, Vol. 44 No. 11/12, pp. 1700-1724.

Argo, J.J., Dahl, D.W., and Morales, A.C. (2006), “Consumer contamination: How consumers react to products touched by others”, Journal of Marketing, Vol. 70 No. 2, pp. 81-94.

Bagga, C., Bendle, N., and Cotte, J. (2019), “Object valuation and non-ownership possession: how renting and borrowing impact willingness-to-pay", Journal of the Academy of Marketing Science, Vol. 47 No. 1, pp. 97-117.

Barnes, S.J., and Mattsson, J. (2017), “Understanding collaborative consumption: Test of a theoretical model", Technological Forecasting and Social Change, Vol. 118 No. 1, pp. 281-292.

Basselier, R., Langenus, G., and Walravens, L. (2018), "The rise of the sharing economy," National Bank of Belgium - Economic Review, September, available at https://www.nbb.be/doc/ts/publications/economicreview/2018/ecoreviii2018_h3.pdf (accessed 7 March 2019).

Belk, R.W. (2014), "You are what you can access: Sharing and collaborative consumption online", Journal of Business Research, Vol. 67 No. 8, pp. 1595-1600.

Belk, R.W., and Llamas, R. (2012), “The nature and effects of sharing in consumer behavior”, in Mick, D., Pettigrew, S., Pechmann, C., and Ozanne, J. (Eds), Transformative Consumer Research for Personal and Collective Well-Being, Routledge, New York, NY, pp. 625-646. 
Benoit, S., Baker, T.L., Bolton, R.N., Gruber, T., and Kandampully, J. (2017), “A triadic framework for collaborative consumption (CC): Motives, activities and resources and capabilities of actors", Journal of Business Research, Vol. 79 No. 1, pp. 219-227.

Braun, V., and Clarke, V. (2006), "Using thematic analysis in psychology”, Qualitative Research in Psychology, Vol. 3 No. 2, pp. 77-101.

Bucher, E., Fieseler, C., and Lutz, C. (2016), "What's mine is yours (for a nominal fee)Exploring the spectrum of utilitarian to altruistic motives for Internet-mediated sharing”, Computers in Human Behavior, Vol. 62 No. 1, pp. 316-326.

Claudy, M., Garcia, R., and O’Driscoll, A. (2015), “Consumer resistance to innovation: A behavioral reasoning perspective”, Journal of the Academy of Marketing Science, Vol. 43 No. 4, pp. 528-544.

Conchar, M.P., Zinkhan, G.M., Peters, C., and Olavarrieta, S. (2004), “An integrated framework for the conceptualization of consumers' perceived-risk processing", Journal of the Academy of Marketing Science, Vol. 32 No. 4, pp. 418-436.

Davidson, A., Habibi, M.R., and Laroche, M. (2018), "Materialism and the sharing economy: A cross-cultural study of American and Indian consumers", Journal of Business Research, Vol. 82 No. 1, pp. 364-372.

Davis, F, Bagozzi, R., and Warshaw, P. (1989), "User acceptance of computer technology: A comparison of two theoretical models", Management Science, Vol. 35 No. 8, pp. 982-1003.

Dellaert, B. (2019), “The consumer production journey: marketing to consumers as co-producers in the sharing economy", Journal of the Academy of Marketing Science, Vol. 47 No. 2, pp $238-254$. 
Eckhardt, G., and Bardhi, F. (2015), “The sharing economy isn't about sharing at all”, Harvard Business Review, 28 January, available at https://hbr.org/2015/01/the-sharing-economyisnt-about-sharing-at-all (accessed 7 November 2018).

Eckhardt, G., Houston, M.B., Jiang, B., Lamberton, C., Rindfleisch, A., and Zervas, G. (2019), "Marketing in the sharing economy", Journal of Marketing, Vol. 83 No. 5, pp. 5-27.

Eisenmann, T., Parker, G., and Van Alstyne, M.W. (2006), "Strategies for two-sided markets", Harvard Business Review, Vol. 84 No. 10, pp. 92-101.

Fehrer, J.A., Woratschek, H., and Brodie, R.J. (2018a), “A systemic logic for platform business models", Journal of Service Management, Vol. 29 No. 5, pp. 546-568.

Fehrer, J.A., Benoit, S., Aksoy, L., Baker, T.L., Bell, S.J., Brodie, R.J., and Marimuthu, M. (2018b), "Future scenarios of the collaborative economy: Centrally orchestrated, social bubbles, or decentralized autonomous?", Journal of Service Management, Vol. 29 No. 5, pp. 859-882.

Fishbein, M., and Ajzen, I. (1975), Belief, attitude, intention, and behavior: An introduction to theory and research, Addison-Wesley, Reading, MA.

Gremler, D. (2004), “The critical incident technique in service research”, Journal of Service Research, Vol. 7 No. 1, pp. 65-89.

Griskevicius, V., and Kenrick, D.T. (2013), "Fundamental motives: How evolutionary needs influence consumer behavior", Journal of Consumer Psychology, Vol. 23 No. 3, pp. 372386.

Guyader, H. (2018), "No one rides for free! Three styles of collaborative consumption”, Journal of Services Marketing, Vol. 32 No. 6, pp. 692-714. 
Habibi, M.R., Kim, A., and Laroche, M. (2016), "From sharing to exchange: An extended framework of dual modes of collaborative nonownership consumption", Journal of the Association for Customer Research, Vol. 1 No. 2, pp. 277-294.

Hamari, J., Sjöklint, M., and Ukkonen, A. (2016), “The sharing economy: Why people participate in collaborative consumption", Journal of the Association for Information Science and Technology, Vol. 67 No. 9, pp. 2047-2059.

Hartl, B., Hofmann, E., and Kirchler, E. (2016), “Do we need rules for 'what's mine is yours'? Governance in collaborative consumption communities", Journal of Business Research, Vol. 69 No. 8, pp. 2756-2763.

Hazée, S., Delcourt, C., and Van Vaerenbergh, Y. (2017), "Burdens of access: Understanding customer barriers and barrier-attenuating practices in access-based services", Journal of Service Research, Vol. 20 No. 4, pp. 441-456.

Hazée, S., Van Vaerenbergh, Y., Delcourt, C., and Warlop, L. (2019), "Sharing goods? Yuck, no! An investigation of consumers' contamination concerns about access-based services," Journal of Service Research, Vol. 22 No. 3, pp. 256-271.

Heidenreich, S., and Kraemer, T. (2016), “Innovations — doomed to fail? Investigating strategies to overcome passive innovation resistance", Journal of Product Innovation Management, Vol. 33 No. 3, pp. 277-297.

Hesse-Biber, S. (2010), “Qualitative approaches to mixed method practice”, Qualitative Inquiry, Vol. 16 No. 6, pp. 455-468.

Homburg, C., Jozić, D., and Kuehnl, C. (2017), “Customer experience management: Toward implementing an evolving marketing concept", Journal of the Academy of Marketing Science, Vol. 45 No. 3, pp. 377-401. 
Kahneman, D., and Tversky, A. (1979), "Prospect theory: An analysis of decision under risk". Econometrica, Vol. 47 No. 2, pp. 263-291.

Kapitan, S., and Bhargave, R. (2013), "Navigating residue sensitivity in the used goods marketplace", Psychology and Marketing, Vol. 30 No. 4, pp. 305-317.

Karahanna, E., Agarwal, R., and Angst, C. (2006), "Reconceptualizing compatibility beliefs in technology acceptance research", MIS Quarterly, Vol. 30 No. 4, pp. 781-804.

Kitzinger, J. (1995), “Qualitative research: Introducing focus groups”, British Medical Journal, Vol. 311 No. 7000 , pp. 299-302.

Kleijnen, M., Lee, N., and Wetzels, M. (2009), “An exploration of consumer resistance to innovation and its antecedents", Journal of Economic Psychology, Vol. 30 No. 3, pp. 344357.

Kumar, V, Lahiri, A., and Bahadir Dogan, O. (2018), “A strategic framework for a profitable business model in the sharing economy", Industrial Marketing Management, Vol. 69 No. 1, pp. 147-160.

Lamberton, C., and Rose, R. (2012), "When is ours better than mine? A framework for understanding and altering participation in commercial sharing systems", Journal of Marketing, Vol. 76 No. 4, pp. 109-125.

Lamberton, C., and Stephen, A.T. (2016), "A thematic exploration of digital, social media, and mobile marketing: Research evolution from 2000 to 2015 and an agenda for future inquiry", Journal of Marketing, Vol. 80 No. 6, pp. 146-172.

Laukkanen, T. (2016), “Consumer adoption versus rejection decisions in seemingly similar service innovations: The case of the Internet and mobile banking”, Journal of Business Research, Vol. 69 No. 7, pp. 2432-2439. 
Lawson, S., Gleim, M., Perren, R., and Hwang, J. (2016), "Freedom from ownership: An exploration of access-based consumption", Journal of Business Research, Vol. 69 No. 8, pp. $2615-2623$.

Lehdonvirta, V., Kässi, O., Hjorth, I., Barnard, H., and Graham, M. (2019), “The global platform economy: A new offshoring institution enabling emerging-economy microproviders”, Journal of Management, Vol. 45 No. 2, pp. 567-599.

Lievens, F., and Slaugher, J.E. (2016), “Employer image and employer branding: What we know and what we need to know", Annual Review of Organizational Psychology and Organizational Behavior, Vol. 3, pp. 407-440.

Light, S. E. (2018), “The role of the federal government in regulating the sharing economy”, in Davidson, N., Finck, L., and Infranca, J. (Eds.), Handbook on the Law of the Sharing Economy, University Press, Cambridge.

Lu, C., and Kandampully, J. (2016), "What drives customers to use access-based sharing options in the hospitality industry?", Research in Hospitality Management, Vol. 6 No. 2, pp.119126.

Lutz, C., and Newlands, G. (2018), “Consumer segmentation within the sharing economy: The case of Airbnb", Journal of Business Research, Vol. 88 No. 1, pp. 187-196.

Martin, C. J. (2016), “The sharing economy: A pathway to sustainability or nightmarish form of neoliberal capitalism?”, Ecological Economics, Vol. 121 No. 1, pp. 149-159.

Martin, D., Gustafsson, A., and Choi, S. (2016), "Service innovation, renewal, and adoption/rejection in dynamic global contexts", Journal of Business Research, Vol. 69 No. 7, pp. 2397-2400. 
Milanova, V., and Maas, P. (2017), "Sharing intangibles: Uncovering individual motives for engagement in a sharing service setting”, Journal of Business Research, Vol. 75 No. 1, pp. 159-171.

Moeller, S., and Wittkowski, K. (2010), “The burdens of ownership: Reasons for preferring renting”, Managing Service Quality, Vol. 20 No. 2, pp. 176-191.

Möhlmann, M. (2015), “Collaborative consumption: Determinants of satisfaction and the likelihood of using a sharing economy option again", Journal of Customer Behaviour, Vol. 14 No. 3, pp. 193-207.

Morales, A.C., Dahl, D.W., and Argo, J.J. (2018), “Amending the law of contagion: A general theory of property transference", Journal of the Association for Consumer Research, Vol. 3, No. 4, pp. 555-565.

Morgan, D.L. (1997). Focus groups as a qualitative research (2 ${ }^{\text {nd }}$ ed.), Sage Publications, Thousand Oaks, London.

Needleman, S.E., and Loten, A. (2014), "Startups want to be the next Airbnb, Uber", The Wall Street Journal, 7 May, available at http://on.wsj.com/2oFNdo8 (accessed 9 November 2018).

Parente, R., Geleilate, J.-M., and Rong, K. (2018), “The sharing economy globalization phenomenon: A research agenda", Journal of International Management, Vol. 24 No. 1, pp. 52-64.

Patton, M.Q. (2014). Qualitative Research and Evaluation Methods, Sage Publications, Thousand Oaks, CA. 
Peres, R., Muller, E., and Mahajan, V. (2010), “Innovation diffusion and new product growth modes: A critical review and research directions", International Journal of Research in Marketing, Vol. 27 No. 2, pp. 91-106.

Perren, R., and Kozinets, R. (2018), "Lateral exchange markets: How social platforms operate in a networked economy”, Journal of Marketing, Vol. 82 No. 1, pp. 20-36.

Ram, S., and Sheth, J. (1989), “Consumer resistance to innovations: The marketing problem and its solutions", Journal of Consumer Marketing, Vol. 6 No. 2, pp. 5-14.

Randhawa, K, Wilden, R., and Hohberger, J. (2016), “A bibliometric review of open innovation: Setting a research agenda", Journal of Product Innovation Management, Vol. 33 No. 6, pp. $750-772$.

Reynoso, J., Kandampully, J., Fan, X., Paulose, H. (2015), “Learning from socially driven service innovation in emerging economies", Journal of Service Management, Vol. 26 No. 1, pp. 156-176.

Rogers, E.M. (1976), "New product adoption and diffusion”, Journal of Consumer Research, Vol. 2 No. 4, pp. 290-301.

Rust, R.T., and Cooil, B. (1994), "Reliability measures for qualitative data: Theory and implications", Journal of Marketing Research, Vol. 31 No. 1, pp. 1-14.

Schaefers, T., Wittkowski, K., Benoit, S., and Ferraro, R. (2016), “Contagious effects of customer misbehavior in access-based services”, Journal of Service Research, Vol. 19 No. 1, pp. 3-21.

Strauss, A., and Corbin, J. (1998). Basics of Qualitative Research: Techniques and Procedures for Developing Grounded Theory (2 ${ }^{\text {nd }}$ ed.), Sage Publications, Newbury Park, CA. 
Subramony, M., Solnet, D., Groth, M., Yagil, D., Hartley, N., Kim, P.C., and Gobulovskaya, M. (2018), “Service work in 2050: Toward a work ecosystems perspective", Journal of Service Management, Vol. 29 No. 5, pp. 956-974.

Talke, K., and Heidenreich, S. (2014), "How to overcome pro-change bias: Incorporating passive and active innovation resistance in innovation decision models", Journal of Product Innovation Management, Vol. 31 No. 5, pp. 894-907.

Täuscher, K., and Kietzmann, J. (2017), “The rise of the sharing economy”, MIS Quarterly Executive, Vol. 16 No. 4, pp. 253-264.

Taylor, M. (2000), “Cultural variance as a challenge to global public relations: A case study of the Coca-Cola scare in Europe”, Public Relations Review, Vol. 26 No. 3, 277-293.

Tussyadiah, I.P. (2016), "Factors of satisfaction and intention to use peer-to-peer accommodation”, International Journal of Hospitality Management, Vol. 55 No. 1, pp. 7080.

Tussyadiah, I.P., and Pesonen, J. (2018), “Drivers and barriers of peer-to-peer accommodation stay: An exploratory study with American and Finnish travellers”, Current Issues in Tourism, Vol. 21 No. 6, pp. 1-18.

Venkatesh, V., Thong, J.Y.L., and Xu, X. (2012), “Consumer acceptance and use of information technology: Extending the unified theory of acceptance and use of technology", MIS Quarterly, Vol. 36 No. 1, pp. 157-178.

Wallendorf, M., and Belk, R.W. (1989), “Assessing trustworthiness in naturalistic consumer research”, in Hirschman, E. C. (Ed.), Interpretive Consumer Research, Association for Consumer Research, Provo, UT, pp. 179-185. 
Westaby, J. D. (2005), “Behavioral reasoning theory: Identifying new linkages underlying intentions and behavior", Organizational Behavior and Human Decision Processes, Vol. 98 No. 2, pp. 97-120.

Wilhelms, M.P., Merfeld, K., and Henkel, S. (2017), "Yours, mine, and ours: A user-centric analysis of opportunities and challenges in peer-to-peer asset sharing”, Business Horizons, Vol. 60 No. 6, pp. 771-781.

Zervas, G., Proserpio, D., and Byers, J. (2017), “The rise of the sharing economy: Estimating the impact of Airbnb on the hotel industry", Journal of Marketing Research, Vol. 54 No. 5, pp. 687-705. 
Table 1: Overview of existing research fields and contribution of this study

\begin{tabular}{|c|c|c|c|c|}
\hline Barrier & Dimension & $\begin{array}{l}\text { Traditional } \\
\text { innovation }^{1}\end{array}$ & $\begin{array}{c}\text { Access- } \\
\text { based } \\
\text { services }^{2}\end{array}$ & $\begin{array}{l}\text { Collaborative } \\
\text { consumption } \\
\text { (this study) }^{3}\end{array}$ \\
\hline \multicolumn{5}{|c|}{ Functional barriers } \\
\hline \multirow[t]{4}{*}{ Complexity } & Understanding & $\checkmark$ & $\checkmark$ & $\checkmark$ \\
\hline & Usage & $\checkmark$ & $\checkmark$ & $\checkmark$ \\
\hline & Accessibility & & $\checkmark$ & $\checkmark$ \\
\hline & Transaction organization & & $\checkmark$ & $\checkmark$ \\
\hline \multirow[t]{2}{*}{ Value } & Economic value & $\checkmark$ & & $\checkmark$ \\
\hline & Relative advantage & $\checkmark$ & & $\checkmark$ \\
\hline \multirow[t]{6}{*}{ Risk } & Asset performance & $\checkmark$ & $\checkmark$ & $\checkmark$ \\
\hline & Technology performance & $\checkmark$ & $\checkmark$ & $\checkmark$ \\
\hline & Actor* performance & & $\checkmark$ & $\checkmark$ \\
\hline & Personal safety & & & $\checkmark$ \\
\hline & Privacy & & & $\checkmark$ \\
\hline & Social interaction & & & $\checkmark$ \\
\hline \multicolumn{5}{|c|}{ Psychological barriers } \\
\hline \multirow[t]{4}{*}{ Compatibility } & Usage patterns & $\checkmark$ & $\checkmark$ & $\checkmark$ \\
\hline & Social norms and values & $\checkmark$ & $\checkmark$ & $\checkmark$ \\
\hline & Previous experience & $\checkmark$ & $\checkmark$ & $\checkmark$ \\
\hline & One's lifestyle & $\checkmark$ & $\checkmark$ & $\checkmark$ \\
\hline \multirow[t]{2}{*}{ Contamination } & Actual physical contact & & $\checkmark$ & $\checkmark$ \\
\hline & Imagined physical contact & & $\checkmark$ & $\checkmark$ \\
\hline \multirow[t]{3}{*}{ Image } & Firm brand & $\checkmark$ & $\checkmark$ & $\checkmark$ \\
\hline & Innovation category & $\checkmark$ & $\checkmark$ & $\checkmark$ \\
\hline & Personal brand/reputation & & & $\checkmark$ \\
\hline \multirow[t]{3}{*}{ Responsibility } & One's usage of the innovation & & $\checkmark$ & $\checkmark$ \\
\hline & Previous customer's usage & & $\checkmark$ & $\checkmark$ \\
\hline & Actor* usage behavior & & & $\checkmark$ \\
\hline
\end{tabular}

Notes. *Actor refers to either customer or peer service provider, depending on the perspective taken. ${ }^{1}$ Barriers identified in prior research on traditional product and service innovations (e.g., Kleijnen et al., 2009; Talke and Heidenreich, 2014). ${ }^{2}$ Barriers identified in prior research on access-based service innovations (Hazée et al., 2017). ${ }^{3}$ Barriers associated with collaborative consumption, identified in this study. 


\begin{tabular}{|c|c|c|c|c|c|c|}
\hline \multicolumn{7}{|c|}{ A: Focus group respondents } \\
\hline \multirow[b]{2}{*}{ ID* } & \multirow[b]{2}{*}{ FG\# } & \multirow[b]{2}{*}{ Gender } & \multirow[b]{2}{*}{ Age } & \multirow[b]{2}{*}{ Profession } & \multicolumn{2}{|c|}{ Prior experience $* *$} \\
\hline & & & & & Customer & Peer service provider \\
\hline 1 & 1 & Female & 22 & Student & $\checkmark$ & $x$ \\
\hline 2 & 1 & Female & 24 & Employed & $\checkmark$ & $x$ \\
\hline 3 & 1 & Female & 25 & Employed & $\checkmark$ & $x$ \\
\hline 4 & 1 & Female & 23 & Student & $\checkmark$ & $x$ \\
\hline 5 & 1 & Female & 24 & Employed & $\checkmark$ & $x$ \\
\hline 6 & 1 & Female & 22 & Student & $\checkmark$ & $x$ \\
\hline 7 & 2 & Male & 22 & Student & $x$ & $x$ \\
\hline 8 & 2 & Male & 23 & Student & $x$ & $x$ \\
\hline 9 & 2 & Male & 22 & Student & $\checkmark$ & $x$ \\
\hline 10 & 2 & Male & 22 & Student & $\checkmark$ & $x$ \\
\hline 11 & 2 & Male & 22 & Student & $\checkmark$ & $x$ \\
\hline 12 & 2 & Male & 22 & Student & $\checkmark$ & $x$ \\
\hline 13 & 3 & Female & 22 & Student & $\checkmark$ & $x$ \\
\hline 14 & 3 & Female & 22 & Student & $\checkmark$ & $x$ \\
\hline 15 & 3 & Female & 23 & Student & $\checkmark$ & $x$ \\
\hline 16 & 3 & Female & 22 & Employed & $\checkmark$ & $x$ \\
\hline 17 & 3 & Female & 22 & Student & $\checkmark$ & $x$ \\
\hline 18 & 4 & Female & 63 & Retired & $x$ & $x$ \\
\hline 19 & 4 & Female & 53 & Self-employed & $x$ & $x$ \\
\hline 20 & 4 & Female & 62 & Retired & $x$ & $x$ \\
\hline 21 & 4 & Female & 54 & Employed & $x$ & $x$ \\
\hline 22 & 4 & Female & 54 & Self-employed & $\checkmark$ & $\checkmark$ \\
\hline 23 & 4 & Male & 56 & Self-employed & $x$ & $x$ \\
\hline 24 & 4 & Male & 53 & Self-employed & $x$ & $x$ \\
\hline 25 & 5 & Female & 54 & Employed & $\checkmark$ & $x$ \\
\hline 26 & 5 & Female & 57 & Employed & $x$ & $x$ \\
\hline 27 & 5 & Female & 51 & Employed & $\checkmark$ & $x$ \\
\hline 28 & 5 & Female & 56 & Employed & $x$ & $x$ \\
\hline 29 & 5 & Female & 55 & Employed & $\checkmark$ & $x$ \\
\hline 30 & 6 & Female & 22 & Student & $\checkmark$ & $x$ \\
\hline 31 & 6 & Female & 22 & Student & $\checkmark$ & $x$ \\
\hline 32 & 6 & Female & 22 & Student & $\checkmark$ & $x$ \\
\hline 33 & 6 & Female & 22 & Student & $\checkmark$ & $x$ \\
\hline 34 & 6 & Male & 22 & Student & $\checkmark$ & $x$ \\
\hline 35 & 6 & Male & 23 & Student & $\checkmark$ & $x$ \\
\hline 36 & 6 & Male & 22 & Student & $\checkmark$ & $x$ \\
\hline
\end{tabular}




\begin{tabular}{llllll}
\hline & \multicolumn{5}{c}{ B: In-depth interview respondents } \\
\hline & & & & \multicolumn{2}{c}{ Prior experience** } \\
ID* & Gender & Age & Profession & Customer & Peer service provider \\
\hline 37 & Male & 31 & Employed & $\checkmark$ & $\times$ \\
38 & Female & 40 & Employed & $\checkmark$ & $\checkmark$ \\
39 & Female & 28 & Student & $\checkmark$ & $\checkmark$ \\
40 & Female & 36 & Employed & $\checkmark$ & $\checkmark$ \\
41 & Female & 21 & Student & $\checkmark$ & $\checkmark$ \\
42 & Female & 38 & Employed & $\checkmark$ & $\checkmark$ \\
43 & Male & 29 & Employed & $\checkmark$ & $\times$ \\
44 & Female & 30 & Self-employed & $\times$ & $\times$ \\
45 & Male & 23 & Student & $\checkmark$ & $\checkmark$ \\
46 & Female & 21 & Student & $\checkmark$ & $\times$ \\
47 & Female & 33 & Employed & $\times$ & $\times$ \\
48 & Male & 29 & Employed & $\checkmark$ & $\times$ \\
49 & Male & 28 & Employed & $\checkmark$ & $\checkmark$ \\
50 & Female & 21 & Student & $\checkmark$ & $\times$ \\
\hline
\end{tabular}

Notes. FG = Focus group. *IDs are used to protect the respondent's identity. **Prior experience captures whether the respondent participated at least once in collaborative consumption in the past. 